\title{
Um Novo "Espírito" do Capitalismo? \\ A globalização e seu impacto na difusão do pensamento de gestão neoliberal na Alemanha e nas economias do Leste Asiático
}

\author{
A New "Spirit" of Capitalism? \\ Globalization and its Impact on the Diffusion of Neoliberal Management \\ Thinking in Germany and the East Asian Economies
}

Markus Pohlmanna e Hyun-Chin Lim ${ }^{b}$

\section{Tradução de Rodrigo Cerqueirac}

Resumo A principal corrente da literatura sobre a globalização é bastante clara em seus pressupostos sobre como ela afeta o empreendimento industrial. Presume-se que ela dá origem a companhias transnacionais e, subsequentemente, a uma classe transnacional de executivos, que se valem do pensamento de gestão neoliberal para acelerar a transformação neoliberal da economia. Este artigo submete tais pressupostos enraizados a um forte teste empírico ao analisar quão transnacionais são as trajetórias de vida de 475 CEOs dos 100 maiores grupos industriais, tanto na Alemanha quanto na Coreia do Sul, Japão e China. Além disso, tendo realizado 148 entrevistas aprofundadas com os CEOs que ocupam os cargos mais altos, o artigo pergunta se há, de fato, um espírito neoliberal do capitalismo em funcionamento. Os resultados indicam que um pensamento de gestão neoliberal não está emergindo e que os altos executivos não são os operadores que levam a uma economia orientada para o mercado financeiro. Embora o pensamento de gestão neoliberal tenha tido algum impacto na alta gerência alemã, os vários sistemas empresariais no Leste Asiático indicam o predomínio de esquemas culturais mais nativos.

Palavras-chave Elites Econômicas; Novo Espírito do Capitalismo; Neoliberalismo; Globalização; Alta Gerência; Empreendimento/Empresa Industrial.

a Professor de Sociologia na Universidade de Heidelberg, Alemanha. Depois de seu doutorado, permaneceu muitos anos no exterior, pesquisando nos EUA, Coreia do Sul, Taiwan, Singapura e Hong Kong. Uma de suas publicações mais recentes é: Pohlmann, Markus; Yang, Jonghoe; LeE, Jong-Hee (Orgs.) Citizenship and Migration in Europe and Asia: The Flow of Migrants and the Perception of Citizenship. Heidelberg: Springer, 2013. E-mail: markus. pohlmann@soziologie. uni-heidelberg.de.

b Professor de Sociologia, Diretor fundador do Centro Asiático (Asia Center) e ex-diretor da Faculdade de Ciências Sociais da Universidade Nacional de Seul, na Coreia do Sul. Dentre suas publicações recentes, incluem-se: Lim, Hyun-Chin (Org.) The Global Challenges in Asia, Seoul and Seattle. Seoul: Seoul National University Press e Global Civil Society: Theories and Practices. Seoul: Nanam. E-mail: hclim@snu.ac.kr.

c Doutor em Teoria e História Literária pela Unicamp. Atualmente realiza pesquisa de pós-doutorado no Departamento de Sociologia da Universidade de São Paulo, com pesquisa financiada pela Fapesp. 
Abstract Mainstream globalization literature is quite clear in its assumptions of how globalization affects industrial enterprise. It is presumed to give rise to transnational companies and subsequently, to a transnational class of managers, who use neoliberal management thinking to accelerate the neoliberal transformation of the economy. The article puts these engrained assumptions to strong empirical test by analysing how transnational the life courses of 475 CEOs of the Top 100 industrial company groups in Germany as well as in Korea, Japan, and China are. Furthermore, having carried out 148 in-depth interviews with Top CEOs, the article asks if in fact a neoliberal spirit of capitalism is at work. The findings indicate that neoliberal management thinking is not emerging and that top managers are not the switchmen leading towards a financial market-driven economy. Although neoliberal management thinking has had some impact on German top managers, the various business systems in East Asia indicate the dominance of more indigenous cultural frames.

Keywords Economic Elites; New Spirit of Capitalism; Neoliberalism; Globalization; Top-Management; Industrial Enterprises.

\section{INTRODUÇÃo}

A discussão sobre o "espírito do capitalismo"1, por um lado, é bastante antiga. Por outro, nós não sabemos muito a respeito da mentalidade coletiva das elites econômicas que constituem esse espírito e da sua transformação ao longo do tempo (Boltanski \& Chiapello, 1999; 2005; Lim \& Kim, 2007; Du Gay \& Morgan, 2013; Pohlmann, 2014). Embora existam alguns estudos globais sobre as atitudes dos executivos, como o Global Study (House et al., 2004), os Insead Studies (Lanvin \& Evans, 2013; Witt, 2014), os estudos da Harvard Business School (Bloom et al., 2012; NoBEL, 2012) e os IBM Studies (2011), indicando a existência de uma convergência de percepções, resultados generalizáveis sobre a adoção de conceitos pelos executivos ainda não estão disponíveis.

Não obstante, a principal corrente da literatura sobre a globalização é muito clara no que diz respeito aos pressupostos gerais sobre seus efeitos (CASTELLS, 1996; BECK, 1997; MÜNCH, 2009; CARroll, 2010). Basicamente, dois pressupostos mais fortes embasam o argumento de que a globalização da economia e das empresas afeta o "espírito do capitalismo" e seus grupos portadores. Eles são:

1 Sombart (1902, p. 319-20) introduziu, em 1902, o conceito de um "espírito do capitalismo" [Geist des Kapitalismus]. Max Weber (1989) o abraçou e o desenvolveu ainda mais. 
1) O de que a construção espiritual da economia moderna, atualmente, está fundada de uma maneira nova sobre o neoliberalismo, entendido, no pensamento econômico, como uma forma de orientação radical para o mercado (Willke, 2003; Crouch, 2011; STreeck, 2013).

2) E o de que uma elite econômica global emergente age como precursora desse novo espírito neoliberal no mundo (CAStElls, 1996; SkLAir, 2001; CARroll, 2010), usando novos conceitos e técnicas de gestão (Boltanski \& Chiapello, 2005; Schmidt-Wellenburg, 2009; Crouch, 2011).

Os resultados empíricos, que serão discutidos abaixo, fornecerão provas para apoiar ou contestar essas duas premissas gerais.

O projeto de pesquisa foi financiado, em sua maior parte, pela German Research Association e apoiado pela Asia Research Foundation Grant, que é sustentada pelo Seoul National University Asia Center (\#SNUAC-2014-009). Ele foi executado no Instituto Max Weber da Universidade de Heidelberg, em cooperação com a Universidade Nacional de Seul e a Universidade Sungkyunkwan². Ele procurou se focar no nível mais alto de gestão (CEOs) das maiores companhias do setor manufatureiro em onze países ${ }^{3}$ e buscou analisar suas mentalidades coletivas em relação ao pensamento de gestão neoliberal. O objetivo da pesquisa é explorar "a construção espiritual (ou os fundamentos)" da economia moderna mediante análise do conhecimento coletivo, das normas e dos valores sobre os quais ela está assentada. Recorrendo à teoria do "espírito do capitalismo", o projeto concentrou-se em dois de seus três componentes principais, que, segundo Max Weber, seriam as racionalidades no pensamento econômico e na ação organizacional (deixando de lado, para os propósitos deste artigo, a terceira racionalidade weberiana, a conduta de vida).

Neste texto, os resultados da pesquisa sobre os executivos alemães e suas mentalidades coletivas serão centrais, mas eles também serão comparados com os resultados relacionados às economias do Leste Asiático. Na Alemanha, foram realizadas, ao todo, 82 entrevistas com duas gerações de executivos das maiores companhias industriais, enquanto na Coreia, no Japão e na China, tomados em conjunto, foram feitas 66 entrevistas com executivos do Leste Asiático.

2 Nós gostaríamos de agradecer a Jonghoe Yang, Jonghoe Lee, Jaok Kwon, Sanghui Nam e Yuan Yuan Liu pelo excelente apoio que tivemos na execução desse projeto de pesquisa.

3 Os países: Argentina, Austrália, Áustria, Brasil, China, Alemanha, Índia, Japão, Coreia do Sul, Suíça, EUA. 
$\mathrm{O}$ artigo inicia-se com uma introdução a respeito dos fundamentos teóricos e prossegue perguntando-se em que medida o recrutamento e a experiência dos executivos na Alemanha e no Leste Asiático são globais. O texto, então, questiona a suposição de que eles disseminariam ideias de um pensamento de gestão neoliberal e finaliza ao resumir os resultados por meio de alguns comentários a título de conclusão.

\section{FUNDAMENTOS TEÓRICOS}

Para sua abordagem teórica, o projeto de pesquisa se vale dos achados históricos de Max Weber, mas apenas como um ponto de partida (Pohlmann, 2002; 2005), de modo a se perguntar se está emergindo uma nova formação histórica do espírito do capitalismo. Alinhado com Weber - e em claro contraste com Boltanski e Chiapello (2005) -, o pressuposto geral do projeto é de que o capitalismo moderno gera as normas e valores para a sua própria reprodução (WEBER, 1989, p. 37). Supõe-se que o capitalismo moderno seja em grande parte autônomo na sua auto-reprodução, realizada por meio dos seguintes mecanismos (ScHLUchter, 1996; PohlmanN, 2002): (1) a competição e a seleção de corporações e pessoal, (2) a difusão de ideias e conceitos, e (3) a socialização dos atores centrais e a internalização de racionalidades (WEBER 1989, p. 204). Esses mecanismos servem de base para as questões centrais da pesquisa, indicadores e etapas analíticas (Tabela 1).

Tabela 1. Esquema teórico e passos da análise.

\begin{tabular}{|c|c|c|c|}
\hline Questão & Mecanismo & Indicadores & Passos da análise \\
\hline $\begin{array}{l}\text { Quais companhias } \\
\text { e atores? }\end{array}$ & $\begin{array}{l}\text { Competição e } \\
\text { seleção }\end{array}$ & $\begin{array}{l}\text { Recrutamento global } \\
\text { de CEOs nas } 100 \\
\text { mais importantes } \\
\text { companhias } \\
\text { industriais }\end{array}$ & $\begin{array}{l}\text { Análise da trajetória } \\
\text { de vida dos CEOs } \\
\text { das } 100 \text { mais } \\
\text { importantes } \\
\text { companhias } \\
\text { manufatureiras }\end{array}$ \\
\hline $\begin{array}{l}\text { Quais mentalidades } \\
\text { coletivas? }\end{array}$ & $\begin{array}{l}\text { Difusão, socialização } \\
\text { e internalização }\end{array}$ & $\begin{array}{l}\text { Mentalidades do } \\
\text { pensamento de } \\
\text { gestão neoliberal }\end{array}$ & $\begin{array}{l}\text { Análise das } \\
\text { mentalidades } \\
\text { coletivas de } \\
\text { duas gerações de } \\
\text { executivos }\end{array}$ \\
\hline
\end{tabular}

Desde a perspectiva do projeto de pesquisa, isso já fornece uma resposta à questão levantada por Boltanski e Chipello (2005) sobre como o capitalismo pode motivar seu pessoal, de modo que eles se empenhem no trabalho (Cf. WiLlmot, 2013, p. 108-10). Contudo, sem a realização de entrevistas e contando apenas com 
a literatura de gestão, isso é difícil de ser precisado (Pohlmann, 2014). Ainda assim, o estudo de Boltanski e Chiapello é bastante útil em sua tarefa de explorar a nova formação histórica do espírito do capitalismo (Pohlmann, 2014, p. 13-4).

Para Weber (1989), essa emergência de uma formação histórica pode ser localizada nos níveis da ação econômica, da organização e das máximas de vida. Como mencionado anteriormente, nós nos concentramos apenas nas duas primeiras racionalidades (Tabela 2).

Tabela 2. Racionalidades do capitalismo e o desafio de agir de acordo.

\begin{tabular}{|l|l|l}
\multicolumn{1}{c|}{ Racionalidades } & \multicolumn{1}{c}{ Desafios } & \multicolumn{1}{c}{ Indicadores selecionados } \\
\hline Ação econômica & $\begin{array}{l}\text { Como devo agir em um } \\
\text { ambiente econômico } \\
\text { espećfico? }\end{array}$ & $\begin{array}{l}\text { Orientações do mercado } \\
\text { financeiro }\end{array}$ \\
\hline Atividades organizacionais & $\begin{array}{l}\text { Como devo liderar } \\
\text { a companhia e os } \\
\text { empregados? }\end{array}$ & Estilo de liderança \\
\hline
\end{tabular}

Com isso, o projeto de pesquisa investiga as rotinas e os roteiros coletivos que guiam as interpretações dos executivos, assim como suas buscas por soluções para problemas objetivos comuns que eles encontram em sua profissão. A principal orientação dessa abordagem também deriva de Max Weber, a quem interessava as ideias e princípios habituais que compõem o espírito do capitalismo. Ele distinguia entre os ensinamentos e os dogmas que constituem o "espírito objetivo" e as ideias, máximas e práticas internalizadas que formam o "espírito subjetivo". Na maioria das vezes, essa parte do espírito do capitalismo assume a forma de hábito, é rotinizada e amplamente tida como certa. Isso se deve ao fato de que de acordo com Alfred Schütz (1982) e Schütz \& Luckmann (1994), que levaram as ideias de Weber adiante - os conteúdos são preenchidos a partir de um estoque de conhecimento coletivo. O conceito de "mentalidades coletivas", portanto, afirma que rotinas e roteiros (como partes importantes da mentalidade coletiva em uso) não são apenas o produto das intenções individuais dos atores, mas também um produto social de suas respectivas culturas, incorporadas por intermédio de vários processos de tipificação e institucionalização (SchüTZ, 1982; SchüTZ \& LuckmanN, 1994). Assim, o projeto de pesquisa não está apenas interessado na análise dos grupos de suporte do novo espírito do capitalismo, mas busca, adicionalmente, responder à questão: com que força seus roteiros coletivos refletem os princípios do pensamento de gestão neoliberal? 


\section{METODOLOGIA}

Como exatamente devem ser testados os dois pressupostos da principal corrente da literatura sobre globalização? Antes de tudo, foi feita uma seleção das economias mais avançadas em duas das mais proeminentes regiões econômicas do mundo: Coreia do Sul, Japão e China, no Leste Asiático; e Alemanha, na Europa. Depois, dentro desses países, visaram-se os CEOs dos 100 empresas industriais mais importantes. As companhias industriais se tornaram o foco da pesquisa, por serem ainda muito importantes na "economia real"4, e por que elas devem ser as pioneiras na adoção de técnicas (neoliberais) de gestão. Tratam-se de grandes companhias que representam diferentes ramos industriais, como montadoras de veículos, indústria química, construção naval e assim por diante. Em terceiro lugar, através de um modelo de métodos mistos, uma variedade de métodos de pesquisa foi usada para analisar a ascensão das elites globais e a "construção espiritual" do capitalismo industrial, de modo a testar os dois pressupostos da literatura sobre a globalização:

1) O pressuposto das "Elites Globais": ao realizar uma análise padronizada das trajetórias de vida dos CEOs, em posições de comando nas 100 mais importantes companhias industriais em cada país (usando fontes da internet, bancos de dados e currículos), 104 casos na Alemanha e 371 na Coreia do Sul, Japão e China, ao todo; o objetivo foi descobrir se pessoas com educação ou experiência internacional similar eram as selecionadas para essas posições de liderança.

2) O pressuposto do "Espírito Único": ao realizar 82 entrevistas aprofundadas com os CEOs na Alemanha e 66 nas economias do Leste Asiático, foi feita uma comparação das estruturas subjacentes de conhecimento, normas e valores coletivos sobre as quais são assentadas as ações de gestão ao longo de duas gerações de executivos ${ }^{5}$.

Contando com os dados da nossa análise padronizada da trajetória de vida, as amostras das entrevistas foram selecionadas usando um método de amostragem

4 Na Alemanha, quase metade das 100 maiores companhias (46\%) são industrias (incluindo a manufatureira, de energia e de construção), enquanto que na Coreia do Sul esse número, em 2012, é de 60\%, no Japão, 41\%, e na China, 38\%.

5 O projeto de pesquisa compara os executivos na ativa ao longo das décadas de 1980 e 1990, os quais alguns ainda permanecem em atividade (nascidos entre 1930-1949), e os CEOs das grandes empresas que estão na ativa no momento (nascidos entre 1950-1969). 
por cota proporcional, relacionado com idade, sexo e atividades internacionais dos CEOs (ver Tabela 3-1, no Apêndice). Selecionar uma amostragem probabilística não é possível nesse campo, porque não se pode selecionar ao acaso os entrevistados dentro da população alvo de CEOs das 100 mais importantes companhias industriais. Então, de modo a atingir uma representatividade qualitativa das amostragens, a melhor solução pareceu ser empregar, nessa medida, uma amostragem por cota proporcional. As entrevistas na Alemanha foram realizadas entre 2007 e 2009, a maioria antes da crise financeira global, e entre 2013 e 2014. No Leste Asiático, as entrevistas foram conduzidas entre os anos de 2012 e 2014.

Foi implementado, na seleção dos entrevistados, um modelo de faixa de idade, comparando-se três grupos etários: CEOs e ex-CEOs nascidos entre 1930 e 1944; entre 1945 e 1954; e entre 1955 e 1964 (ver Tabela 3-2, no Apêndice). O propósito dessa comparação de grupos etários foi descobrir se haveria um efeito de coorte etário sobre as características das mentalidades coletivas em ação, e, embora o projeto não tenha podido usar de dados longitudinais, avaliar as mudanças nessas mesmas mentalidades coletivas. A análise das mentalidades coletivas (ou padrões de interpretação social) é uma abordagem bem estabelecida na Alemanha e na Europa em geral, relacionada à tradição hermenêutica da sociologia do conhecimento (REICHERTZ, 2004; 2005).

Tabela 3. Número de entrevistas com os CEOs ${ }^{6}$.

\begin{tabular}{|c|c|c|c|}
\hline Número de entrevistas & CEOs na ativa & CEOs aposentados & Total \\
\hline Alemanha & 29 & 53 & 82 \\
\hline Coreia do Sul & 13 & 12 & 25 \\
\hline Japão & 12 & 8 & 20 \\
\hline China & 18 & 3 & 21 \\
\hline Outros & 82 & 41 & 123 \\
\hline Total & 154 & 117 & 271 \\
\hline
\end{tabular}

Ao se valer do termo "mentalidades coletivas" (o termo "Padrão de Interpretação Social” também é usado), faz-se uso da perspectiva do conhecimento socialmente construído (CRESWELL, 2003, p. 08). A análise das mentalidades coletivas (AMC) envolve a reconstrução dos esquemas, hábitos e atitudes coletivas que organizam a produção do conhecimento e as atitudes em um grupo social, uma cultura ou uma sociedade. Isso nos informa como interpretar o mundo, isto é, o que é típico, significante e relevante. Em sua perspectiva clássica, a AMC lida com

6 Os CEOs aposentados são aqueles que desistiram das suas posições nos respectivos 100 maiores grupos empresariais. Em sua maioria, esses CEOs aposentados estão trabalhando enquanto CEOs de outras firmas ou como membros de seus conselhos consultivos. 
as representações coletivas, da forma como Durkheim as denominou (DurkHEIM, 1967, p. 78 ss.), ou com as derivações que Pareto tinha em mente, que podiam ser rastreadas até certos resíduos (PARETO, 1962). Dessa forma, a AMC está interessada, antes de tudo, nas estruturas de conhecimento [knowledge frames] que ajudam os membros de um grupo específico, uma cultura ou uma sociedade a lidar com problemas sociais (OEverman, 1973; 2001). Essas estruturas, hábitos e roteiros são parte de um inventário coletivo de conhecimento, herdado por intermédio da cultura, que é reproduzido e alterado coletivamente (SchüTz \& LuckmanN, 1979; SchÜтz, 1982). Eles são representados pelos membros de um grupo específico, uma cultura ou sociedade, mas nem sempre se tornam parte consciente dos seus conhecimentos individuais. Dentro de uma perspectiva sociológica, as mentalidades coletivas são relevantes para responder a três questões: qual o problema, como nós devemos solucioná-lo e quais são as resoluções boas e ruins? Assim, cada mentalidade coletiva tem uma dimensão cognitiva, normativa e avaliativa, que será reconstruída pelo uso do método de análise de mentalidades coletivas (AMC) (ver Tabela 3-3 no Apêndice). Os padrões manifestos de argumentação articulados por nossos entrevistados ${ }^{7}$ foram relacionados com o esquema de conhecimento dominante. Tal método foi originalmente concebido por Oevermann (2001) e desenvolvido por Ullrich (1999) e Sachweh (2010), e posteriormente aplicado em um modelo de pesquisa internacional sob a orientação de falantes nativos.

\section{ELITES GLOBAIS COMO PRECURSORAS?}

Diz-se que está ocorrendo uma competição acirrada por empregos atraentes, com reputação e remuneração altas, assim como uma "guerra por talentos" entre as nações e entre as companhias para contratar os "melhores cérebros" (APPADURAI, 1998, p. 15; Dreher, 2003, p. 18; Chalamwong, 2005, p. 488). Tomando os pressupostos da principal corrente da literatura sobre globalização como ponto de partida, há três abordagens no debate científico sobre as elites globais ou transnacionais que sustentam fortemente essa ideia:

a) A abordagem das elites globais (CAstells, 1996; Beck, 1997; MÜNCh, 2009 etc.), que implica na ideia de que as elites globais são capazes de produzir seus bens onde os custos são mínimos, estabelecer-se e trabalhar onde a vida é mais confortável e pagar impostos onde eles são menores (BECK, 1997,

7 Isso permitiu ao projeto contar quantos entrevistados articularam um determinado padrão. 
p. 17). Na colocação de Castells (1996, p. 414), "elites são cosmopolitas, o povo é local".

b) A abordagem da classe capitalista transnacional (SkLAIR, 2001; RoBINSON, 2004; 2012; CARroll, 2010 etc.), que tenta demonstrar que os executivos das corporações (SkLAIR, 2001, p. 21) se tornaram mais transnacionais e que o crescente número de interconectores transnacionais indicam a emergência de uma nova classe transnacional (CARroll, 2010, p. 20).

c) A abordagem da carreira sem fronteiras (Sullivan \& Arthur, 2006; Thomas \& INKEN, 2007 etc.), que afirma que a gestão pessoal (em oposição ao desenvolvimento da carreira pela organização) se tornou mais importante e acaba por levar a uma maior mobilidade transnacional de carreira (SUlLivan \& Arthur, 2006, p. 22).

Em cada uma dessas abordagens, os executivos são a personificação da "vanguarda" da globalização. Para testar tal hipótese, o projeto de pesquisa se valeu de vários indicadores. Primeiramente, foi perguntado quantos dos executivos nasceram e foram criados no exterior. Segundo, as empresas para as quais esses executivos estavam trabalhando foram classificadas de modo a se descobrir quantos dos executivos que nasceram no exterior trabalham para companhias domésticas ou para as afiliadas internacionais de companhias multinacionais. Terceiro, as formas mais fracas de internacionalização em companhias da Alemanha e do Leste Asiático foram definidas nos seguintes termos: se os executivos tinham estudado no exterior ou se eles tinham trabalhado uma parte significativa das suas carreiras fora do país. De acordo com esses indicadores, o projeto de pesquisa classificou como carreiras nacionais ou transnacionais apenas aquelas cuja ascensão ou declínio no exterior aconteceu enquanto parte de uma alocação internacional e não como parte do desenvolvimento da carreira dentro da sede da empresa mãe.

\section{EXECUTIVOS ALEMÃES COMO ELITES GLOBAIS?}

No que diz respeito aos CEOs das 30 companhias com melhor performance financeira na bolsa de Frankfurt (DAX-30), as coisas parecem bastante encorajadoras para os defensores da tese da elite global. A análise dos CEOs dessas 30 companhias, em 2012, encontrou 9 executivos de nacionalidade estrangeira (Tabela 3), ou seja, uma taxa de $29 \%$. Essa cota de pouco mais de um quarto será confirmada quando a origem de todos os 189 membros do conselho executivo das 30 companhias for levada em consideração. Em outras palavras, a fatia dos membros 
do conselho executivo de origem estrangeira corresponde a 26,5\%. Essa porcentagem é relativamente alta devido à fusão das atividades de companhias globais.

Contudo, as coisas começam a parecer diferentes quando se vai além das 30 companhias com melhor performance financeira na bolsa de Frankfurt (DAX-30) e se leva em conta, também, as 100 maiores companhias industriais. A percentagem cai, então, para 16\% entre os executivos, e diminui ainda mais quando, através de dados da pesquisa social geral [general social survey] (Mikrosensus) representativa da Alemanha, todas as companhias passam a ser consideradas.

Tabela 4. CEOs na Alemanha nascidos no exterior.

\section{1/2012}

Nascidos no exterior (N)

CEOs das 30 companhias com melhor performance

financeira na bolsa de Frankfurt (Dax 30)

$29,0 \%(9)$

Conselho executivo das 30 companhias com melhor

performance financeira na bolsa de Frankfurt (Dax 30)

100 mais importantes CEOs da indústria

$26,5 \%(51)$

Todos os CEOs das firmas na Alemanha

$16,0 \%(16)$

$8,3 \%(65.000)$

Tabela 5. Estadias no exterior ( $\geq 1$ ano) de executivos alemães por faixa etária.

\begin{tabular}{|c|c|c|}
\hline \multicolumn{1}{|c|}{ Faixa etária } & $1930-1949$ & $1950-1969$ \\
Atividades no exterior & $\mathrm{N}=106$ & $\mathrm{~N}=75$ \\
\hline Estudo no exterior $\geq 1$ ano & $20 \%$ & $25 \%$ \\
\hline Trabalho no exterior $\geq 1$ ano & $17 \%$ & $42 \%$ \\
\hline Total de atividades no exterior & $31 \%$ & $53 \%$ \\
\hline
\end{tabular}

Fonte: Munzinger Archiv (Arquivo de imprensa alemão)

Nas 100 maiores companhias industriais da Alemanha, dos 16 CEOs que nasceram e cresceram no exterior, somente 8 trabalhavam para companhias efetivamente sediadas na Alemanha. Os 8 outros CEOs trabalhavam para grandes empresas estrangeiras. Em sete casos, esses executivos foram enviados pelas companhias multinacionais para administrar uma subsidiária local. Assim, a fatia de executivos "globais" é, na verdade, pequena no que diz respeito a empreendimentos industriais na Alemanha. Não são as elites globais, mas aquelas com uma experiência nacional que dominam.

Essa rejeição empiricamente fundamentada da tese da elite global no que tange à Alemanha não significa, contudo, que não existam efeitos da globalização sobre as companhias e sobre o recrutamento e o padrão da carreira dos executivos. Como veremos mais abaixo, as carreiras se tornaram, de fato, mais internacionais.

A utilização de dados confiáveis de um grande arquivo de jornais na Alemanha (o arquivo Munziger), combinada com os dados das entrevistas, deixou claro que, 
quando se comparam as coortes, a importância de estadias no exterior cresceu (sobre isso, ver a Tabela 4 e, ainda, Dienl \& Dixon, 2005, p. 715-6).

No grupo mais jovem, nascido entre 1950 e 1969, esse número cresce de 31\% para mais da metade de todos os executivos da indústria. Particularmente, a quantidade de executivos que trabalharam no exterior mais do que dobrou. $\mathrm{O}$ aumento no envio de executivos para o exterior, uma espécie de "circulação de cérebros" compulsória, constitui o efeito crucial da globalização. Embora as elites globais ainda não estejam sendo recrutadas ao redor do mundo com tanta frequência, elas efetivamente têm experiência em universidades estrangeiras ou em firmas afiliadas.

\section{ELITES GLOBAIS NO LESTE ASIÁTICO?}

Os resultados da pesquisa para outros países indicam que a Alemanha não é um caso excepcional. Verificou-se que, nos países do Leste Asiático, no todo, 16 dentre 373 CEOs nasceram no exterior. Essa fatia de 6\%, em grande medida, deve-se às políticas chinesas de abertura da economia às grandes companhias transnacionais (CTN), de modo a capitalizar com o conhecimento delas. Na verdade, há somente dois CEOs estrangeiros nas 100 mais importantes companhias manufatureiras chinesas. A maioria dos CEOs nascidos e criados no exterior não só trabalhavam para uma afiliada estrangeira de uma companhia multinacional, como eram, sobretudo, expatriados, isto é, eles foram enviados para esse país como um desafio no desenvolvimento de suas carreiras dentro da empresa sede. Apenas 3 dentre 373 CEOs, uma fatia de mais ou menos $1 \%$, foram recrutados internacionalmente (ver Tabela 5).

Dessa forma, os resultados que dizem respeito às economias do Leste Asiático confirmam os resultados do caso alemão. A quantidade de CEOs recrutados internacionalmente é ainda menor. Se se olha para as outras economias na amostra do projeto de pesquisa, somente na Austrália e na Suíça há maior quantidade de recrutamento internacional de executivos. Ao todo, as quantidades são baixas demais para fornecer fundamentações empíricas para o pressuposto das elites globais. Ela deve ser refutada ao menos no que diz respeito aos CEOs das maiores companhias industriais. 
Tabela 6. Número de CEOs nas economias do Leste Asiático nascidos/criados no exterior.

\begin{tabular}{|l|c|c|c|c|}
\multicolumn{1}{|c|}{ Países (n) } & $\begin{array}{c}\text { CEOs nascidos } \\
\text { no exterior (N) }\end{array}$ & $\begin{array}{c}\text { CEOs nascidos } \\
\text { no exterior em } \\
\text { companhias } \\
\text { domésticas (N) }\end{array}$ & $\begin{array}{c}\text { CEOs nascidos } \\
\text { no exterior nas } \\
\text { CTNs (N) }\end{array}$ & Expatriados (N)* \\
\hline China (146) & $9 \%(14)$ & $0 \%(0)$ & $9 \%(14)$ & $8 \%(12)$ \\
\hline Japão (104) & $4 \%(4)$ & $1 \%(1)$ & $3 \%(3)$ & $2 \%(2)$ \\
\hline Coreia do Sul (121) & $4 \%(5)$ & $0,8 \%(1)$ & $3 \%(4)$ & $3 \%(4)$ \\
\hline Total (371) & $6,1 \%(23)$ & $0,5 \%(2)$ & $5,6 \%(21)$ & $4,8 \%(18)$ \\
\hline
\end{tabular}

* Refere-se àqueles CEOs que trabalham para uma companhia afiliada do exterior e que foram enviados pela empresa sede para ocupar cargo de CEO por um período de tempo determinado.

O mesmo padrão de uma “circulação de cérebros" compulsória como principal efeito da globalização - com exceção da China - também é encontrado nas economias do Leste Asiático. Olhando mais atentamente as permanências no exterior que duraram um ano ou mais, na Coreia do Sul se detecta um forte efeito de coorte, embora se deva observar que existe um número menor de CEOs no grupo etário entre 40 e 49 anos. Assim, quanto mais jovem a faixa etária, maior a quantidade de CEOs que trabalharam e/ou estudaram no exterior e, por isso, internacionalizaram suas carreiras $^{8}$ (ver Tabela 6).

No caso dos executivos japoneses ${ }^{9}$, a taxa de mobilidade por razões educacionais é pequena, mas é possível encontrar o mesmo efeito de coorte no que diz respeito a alocações no exterior por razões profissionais.

Embora a hipótese de uma forte globalização não possa ser sustentada, a hipótese de uma globalização mais fraca, referente à circulação compulsória de cérebros durante a carreira dentro da empresa sede encontra, de fato, suporte nos dados extraídos da análise das trajetórias de vida. Se todos os 1302 casos de CEOs dos 11 países forem levados em consideração, o efeito de coorte é forte e significante e pode ser confirmado.

Tabela 7. Estadia no exterior ( $\geq 1$ ano) de executivos sul-coreanos por faixa etária.

\begin{tabular}{l|l|l|l|l|} 
Faixa etária (N) & 40-49 anos (10) & $50-59$ anos (63) & 60 anos ou + (45) & Total (119)
\end{tabular}

\begin{tabular}{l|l|l|l|l|}
\hline $\begin{array}{l}\text { Estudo no exterior } \\
(\geq 1 \text { ano })\end{array}$ & $90 \%$ & $21 \%$ & $16 \%$ & $25 \%$ \\
\hline $\begin{array}{l}\text { Trabalho no exterior } \\
(\geq 1 \text { ano })\end{array}$ & $50 \%$ & $38 \%$ & $35 \%$ & $38 \%$ \\
\hline
\end{tabular}

8 No que diz respeito à discussão geral sobre o recrutamento da elite no poder na Coreia do Sul, consultar pesquisas de Choi (1993), Dong (1995) e Kim (2005). Sobre o contexto histórico das elites no poder da Coreia do Sul, ver a discussão de Kong (2000).

9 Sobre o recrutamento das elites no Japão, consultar as pesquisas de Mannari (1974) e Cutts (1997). Para pesquisas mais recentes, favor consultar Watanabe e Schmidt (2004) e Schmidt (2005). 
Tabela 8. Estadia no exterior ( $\geq 1$ ano) de executivos japoneses por faixa etária.

\begin{tabular}{l|l|l|l|l|} 
Faixa etária (N) & $40-49$ anos (2) & $50-59$ anos (28) & 60 anos ou + (73) & Total (103)
\end{tabular}

\begin{tabular}{l|c|c|c|c|}
\hline $\begin{array}{l}\text { Estudo no exterior } \\
(\geq 1 \text { ano })\end{array}$ & $0 \%$ & $11 \%$ & $11 \%$ & $11 \%$ \\
\hline $\begin{array}{l}\text { Trabalho no exterior } \\
(\geq 1 \text { ano })\end{array}$ & $100 \%$ & $39 \%$ & $16 \%$ & $24 \%$ \\
\hline
\end{tabular}

\section{UM NOVO ESPÍRITO NEOLIBERAL DO CAPITALISMO?}

Se nenhuma elite global está emergindo e nenhum padrão de recrutamento global significativo está ocorrendo, então como entender a transformação das mentalidades coletivas no sentido de um novo espírito neoliberal do capitalismo? A literatura recente sobre o neoliberalismo compartilha o pressuposto de que a disseminação das ideias neoliberais e uma forte tendência à convergência em direção ao pensamento de gestão neoliberal está em andamento nas regiões centrais da economia mundial (Boltanski \& Chiapello, 2005; Crouch, 2011, p. 92; STREECK, 2013, p. 45-6 e 58-9). Embora numerosos estudos tenham defendido a divergência ou a "dependência da trajetória" nos modelos de gestão de sistemas empresariais (Whitley, 1999; HALl \& Soskice, 2001; AMABLE, 2003, para instituições do Estado de Bem-Estar Social, e ainda LeibFried \& Rieger, 2004), "a literatura de convergência é o ponto de vista estabelecido há mais tempo” (CLEGG, 2012). Para os casos da Alemanha e do Japão, Streeck e Yamamura examinaram se as forças globais do capitalismo anglo-americano estão dando origem a um sistema capitalista unificado e homogêneo (STreEck \& Yamamura, 2003).

O entendimento do neoliberalismo, hoje em dia, diz respeito ao - mais ou menos radical - estabelecimento da coordenação do mercado dentro das firmas, das economias e na transformação de setores do Estado e de outros em direção ao predomínio de uma racionalidade de mercado (WILLKE, 2003, p. 11-5). Um novo neoliberalismo, originado nos EUA, parece estar marchando triunfalmente sobre o mundo (Streeck \& Yamamura, 2003; Willke, 2003, p. 11-5). Até agora, as consequências têm sido vistas na erosão e no recuo do estado do Bem-Estar Social, na privatização de empresas estatais e na desregulamentação do mercado financeiro (CROUCH, 2011; STREECK, 2013). Mas, fora esses pressupostos gerais, a nova repaginação neoliberal do espírito do capitalismo na economia permanece muito pouco determinada (Willke, 2003, p. 11-5; Schmidt-Wellenburg, 2009). Afirma-se, com frequência, que os executivos são promotores dessas novas ideias neoliberais; porém, até agora, nenhuma prova sistemática e empírica a esse respeito foi produzida (Pohlmann, 2014, p. 14). O propósito deste artigo é examinar esse pressuposto, usando dados de entrevistas qualitativas válidas. 
De modo a testar empiricamente a disseminação de valores neoliberais e do pensamento de gestão neoliberal, o projeto se focou na análise dos conceitos de gestão nas últimas três décadas (Schmidt-Wellenburg, 2009, p. 325-35). Para o propósito deste texto, duas importantes características do pensamento de gestão neoliberal foram selecionadas: a) um pensamento econômico movido pelo mercado financeiro (uma mentalidade de mercado financeiro); e b) uma mentalidade de gestão neoliberal com coordenação de mercado dentro da firma e um estilo de liderança movido pelo resultado (Cf. Schmidt-Wellenburg, 2009, p. 327). Essas características compõem as partes mais importantes do pensamento de gestão neoliberal e são acompanhadas por vários conceitos da gestão que são tidos como influentes ao redor do mundo todo (Cf. Schmidt-Wellenburg, 2009, p. 325-35).

Tabela 9. 0 novo pensamento de gestão neoliberal: os indicadores.

\section{A mentalidade do mercado financeiro}

$\Sigma$ Compreensão das empresas como investimentos no mercado financeiro

$\Sigma$ Orientação de valor do acionista e capitalização no mercado

$\Sigma$ Princípios de mercado na cadeia de valor global

A mentalidade de gestão neoliberal

$\Sigma$ Compreensão das empresas como centros de rede de lucros

$\Sigma$ Sistema de indicadores e Benchmarks

$\Sigma$ Liderança orientada para resultados e indicadores de mercado (ambiente de trabalho centrado somente nos resultados)

\section{MENTALIDADE DE MERCADO FINANCEIRO ENTRE EXECUTIVOS ALEMÃES}

Durante as entrevistas, não foram muitos os executivos alemães que deram boas-vindas à economia orientada para o mercado financeiro. Sem nenhuma exceção, para todos os executivos alemães, estava bastante claro que o "Modelo Alemão" tinha mudado consideravelmente durante as últimas décadas e que um bom número de companhias tinha sido exposta às (ir)racionalidades dos mercados financeiros. Somente 1 dentre 65 executivos profissionais mencionou as oportunidades e aberturas que os mercados financeiros proporcionaram às suas empresas; os demais mostraram-se ambivalentes ou majoritariamente contrários (50 entre 65) a uma economia orientada para o mercado financeiro. Todos os 17 empresários dos grandes grupos administrados por famílias na Alemanha viam com bons olhos o fato de que eles não estavam expostos de nenhum modo à lógica dos mercados financeiros. Assim, o desafio de como agir em um ambiente econômico específico e dar lucro às suas firmas não foi respondido - nem antes, nem depois da crise financeira mundial -, com uma forte referência à economia orientada para o mercado financeiro. 
Ao responderem a questões sobre o quão forte é a influência do sistema financeiro e como os CEOs agem de modo a enfrentar os desafios desse sistema, a mentalidade coletiva dominante, articulada em $77 \%$ dos 65 executivos profissionais (não incluindo os 17 empresários de firmas administradas por famílias), foi, no que se refere à economia orientada para o mercado financeiro, uma mentalidade defensiva que "manipula as regras do sistema". Isso pode ser entendido como um roteiro coletivo que defende que sejam seguidos os procedimentos e regras formais do sistema financeiro, mas de modo a burlá-lo pelo bem da sobrevivência e do crescimento da firma. Sua lógica subjacente estava bastante aparente e consistia dos seguintes componentes: 1 . O sistema está mudando em direção a uma economia orientada para o mercado financeiro; 2. A pressão dos acionistas está aumentando, assim como a capacidade de regulação dos gestores de fundos; 3. Isso não é bom para a companhia e para suas estratégias de longo prazo; 4. Os donos e acionistas não agem mais segundo os interesses da companhia, apenas os executivos o fazem; 5. Desse modo, eles têm que cuidar atentamente das aparências e manipular com muito afinco as regras do sistema de maneira a conseguir burlá-lo.

Essa mentalidade defensiva de "manipular as regras do sistema" é fortemente influenciada pela economia orientada para o mercado financeiro; mas não se trata, em essência, de usar os mercados financeiros para resolver problemas econômicos. Trata-se, antes, de defender a companhia contra seus acionistas e contra as irracionalidades dos mercados financeiros, em especial de sua visão "curto-prazista". Os relatórios trimestrais fornecem os indicadores para todos os analistas e para as agências de risco. É por isso que os argumentos contra a economia orientada para o mercado financeiro vinham sendo incisivos e firmes antes da crise financeira mundial e se tornaram ainda mais negativos e defensivos posteriormente. A norma subjacente é a de proteger os interesses das companhias contra acionistas que tentam alcançar ganhos rápidos para passar para as próximas ações quentes do momento. "Claro, os acionistas, em particular os investidores institucionais, têm cada vez mais poder e influência no que diz respeito às estratégias da empresa. Na minha perspectiva, isso não é somente perigoso, porque nós somos controlados de fora, mas também porque isso pode não ser o melhor para toda a companhia e para as suas estratégias de longo prazo" (CEO alemão na ativa, Argentina, 2013, traduzido do alemão pelos autores) ${ }^{10}$.

Contudo, essa não é a história toda. Uma mentalidade agressiva do mercado financeiro pode ser encontrada na Alemanha entre uma minoria de CEOs mais

10 Todas as passagens são citadas segundo a nacionalidade, posição e status do entrevistado, a localização da entrevista e o ano no qual a entrevista foi realizada. Nós não revelamos nenhuma outra informação a fim de preservar o anonimato dos nossos entrevistados. 
jovens, em 3 dentre 25 CEOs no cargo do grupo etário nascido entre 1955 e 1964. Tal mentalidade agressiva pode ser definida como aquela que usa o sistema financeiro de modo a impulsionar a firma, tanto através de uma infusão de capital, quanto se livrando da velha guarda do capitalismo renano (Albert, 1993). Nesse caso, a economia orientada para o mercado financeiro é entendida como vantagem para a firma, no que diz respeito à eficiência econômica, às relações com os investidores e à lucratividade.

\section{MENTALIDADE DE GESTÃO NEOLIBERAL: EXECUTIVOS ALEMÃES E ESTILOS DE LIDERANÇA}

Atualmente, o paternalismo como estilo de liderança está morto nas empresas alemãs. Delegação é a palavra-chave na mentalidade coletiva sobre liderança. Para mais de 90\% dos 82 executivos e empresários, agora é natural que a delegação seja um mecanismo de distribuição de responsabilidades e efetivação de um grau mais alto de participação. O conceito de delegação é entendido como uma combinação de transferência de responsabilidade e do poder de tomar decisões para um ou mais empregados. Geralmente, delegação nas grandes empresas da Alemanha está ligada a mudanças na organização do trabalho, à introdução de novas formas de comunicação, participação e cotas de ações para os empregados. O conceito de delegação é, contudo, enunciado de uma maneira ambivalente por $2 / 3$ dos 82 executivos e empresários. Por um lado, ele é visto como uma maneira da companhia capitalizar sobre o conhecimento de profissionais e pessoal altamente especializado. Por outro, o excesso de delegação é julgado como algo arriscado, que leva a uma perda de controle sobre as orientações estratégicas das atividades da empresa. "Seus desafios no que diz respeito à liderança são, algumas vezes, preto no branco. Este é o chefe e ele tem que decidir. Se você não toma a decisão por si mesmo, você não apenas está perdendo prestígio; você está perdendo também seus apoiadores" (CEO alemão na ativa, Brasil, 2013, traduzido do alemão pelos autores). É por isso que um sistema de indicadores orientado pelo resultado e pelo mercado, bem como benchmarks e avaliações de performance entram em cena. Ao menos para os CEOs nascidos entre 1955 e 1964, o uso desse sistema de indicadores como um enquadramento estratégico de autonomia de decisão é algo natural. "Eu diria que hoje você precisa de uma mistura entre delegação, indicadores de controle e decisões centralizadas. Em nossa companhia, os muros de contenção são claramente definidos pelos sistemas de indicadores; mas, dentro deles, nós delegamos, e as pessoas têm poder de decisão. Estamos fazendo um 
certo processo de controle e equilíbrio (CEO alemão no cargo, Alemanha, 2008, traduzido do alemão pelos autores).

A antiga mentalidade de "conversar com as pessoas e ouvi-las" é uma forma de conhecimento coletivo usado, com mais frequência, por um grupo significante (21 dentre 53) de CEOs aposentados da faixa etária nascida na Alemanha entre 1930 e 1944. De modo a se comunicar e ter informações diretas, grupos-alvo não-hierarquizados precisam ser estabelecidos. O conceito de delegação não diz respeito, então, à transferência do poder de tomar decisões e às responsabilidades, mas sim ao estabelecimento de um padrão de comunicação de baixo para cima.

A nova mentalidade de liderança orientada pelo resultado não é somente articulada pelo grupo de CEOs nascido entre 1955 e 1964, mas, também, por alguns da faixa etária de executivos alemães nascidos entre 1930 e 1944. O conceito de estilo de liderança orientada pelo resultado está baseado em uma avaliação de unidades por sistema de indicadores e benchmarks que ajudam a reduzir intervenções diretas. Um grupo menor de CEOS e empresários aposentados (7 dentre 53 ex-CEOs nascidos entre 1930 e 1944) trabalharam com um sistema para avaliar o desempenho individual e a participação organizada de seus empregados conforme medição de desempenho. Quanto melhor seu desempenho, maior será a transferência do poder de tomar decisões. No nível da organização do trabalho, muitas das 100 mais importantes companhias industriais na Alemanha, como a Volkswagen ou a BMW, estabeleceram um sistema de indicadores e de benchmarks, juntamente com a implementação de centros de lucro. O propósito é definir metas de rendimento para essas unidades, deixando a cargo delas decidir como alcançar cada uma dessas metas. Quanto melhor o seu desempenho e a sua contribuição para a lucratividade da empresa, mais rápido você será promovido e maior será a sua liberdade de tomar decisões. Isso está em perfeita sintonia com a mentalidade de gestão neoliberal.

Um terço dos principais executivos alemães, sobretudo as poucas mulheres empresárias da amostragem, e 12 dentre 25 da faixa etária nascida entre 1955 e 1964 usam a mentalidade coletiva para descrever seu papel de liderança, nomeado pelo projeto como a mentalidade "de técnico do time". Ela é entendida como conceitualização do papel do líder, não como supervisor, mas consultor de um time profissional que não precisa de comando, mas de suporte, conselho e atribuição de responsabilidades. Segundo tal mentalidade, todos os elementos de chefia que sejam diretivos ou impositivos são vistos negativamente. A perspectiva do treino é dominante: dá-se conselhos, apoio e atribuem-se responsabilidades às pessoas. A atribuição da capacidade de "auto-otimização", assim como as possibilidades 
para que profissionais decidam por si mesmos, é o alicerce do novo exemplo de liderança, que se enquadra na teoria de liderança de autogovernança neoliberal (BRÖCKLING, 2005). Ele se tornou radicalmente anti-hierárquico e antipaternalista.

\section{MENTALIDADES COLETIVAS DOS EXECUTIVOS NO LESTE ASIÁTICO}

As entrevistas dos CEOs na Coreia do Sul (N=25), Japão ( $\mathrm{N}=20)$ e China $(\mathrm{N}=21)$ foram realizadas em 2012 e 2013, após a crise financeira global, a qual não causou grandes impactos nas economias chinesa e sul coreana. Contudo, as mentalidades coletivas dos executivos coreanos foram fortemente afetadas por um efeito de período, relacionado com a crise financeira asiática de 1997/1998. Aqueles executivos dos grandes conglomerados empresariais coreanos, que sobreviveram à quebra da economia sul-coreana no final da década de 1990 eram vigorosamente a favor do renovado modelo coreano das empresas administradas por famílias. Ele mantinha as vantagens de um sistema de tomada de decisões rápido e altamente flexível, ainda muito frequentemente "de cima para baixo", mas que se tornou bastante cuidadoso no que diz respeito aos riscos dos mercados financeiros. Até hoje, é quase impossível que um controle externo assuma os grandes grupos empresariais. "Mas, na verdade, está comprovada a eficiência desse tipo de grupo empresarial baseado na propriedade. Está provado que é bastante efetivo em termos de estratégia de longo prazo. [...] Você sabe, é por isso que foi possível chegar em primeiro lugar, porque a empresa coreana baseada na propriedade é bastante consistente, muito concentrada..." (Presidente coreano de uma empresa e CEO na ativa, Coreia do Sul, 2013). Assim, para 20 dentre 24 CEOs sul-coreanos de grandes grupos empresariais da Coreia do Sul, a economia orientada para o mercado financeiro não pareceu ser uma alternativa real para o modelo nacional. Para os outros CEOs, o mercado financeiro em si mesmo não era bem visto, mas a transparência financeira própria a esse sistema era, sim, bem-vinda.

Ao contrário dos coreanos, os 20 executivos japoneses reconheceram que o sistema orientado para o mercado financeiro ganhou força e agora é bastante difundido no Japão. Contudo, nas mentalidades coletivas em vigor é o sistema ocidental que não se encaixa na maneira japonesa de fazer negócios. A maioria dos executivos japoneses, com a exceção de dois casos, não só não defendeu a economia orientada para o mercado financeiro, como a compararou às vantagens dos sistema japonês, o qual, queixaram-se, estava quase perdido. Entre os 20 executivos entrevistados, a mentalidade dominante era oposta ao kabunushi henchô shugi (predomínio do interesse do acionista), preferindo antes o capitalismo do bem comum (kôeki shihon 
shugi). 17 dentre os 20 CEOs disseram que o mais importante é contrabalancear os interesses dos acionistas, empregados, bancos e comunidade. Para 9 dentre os 11 CEOs, da faixa etária nascida entre 1930 e 1944, era muito evidente que o sistema orientado para o mercado financeiro é um sistema ocidental, contrário ao sistema japonês autóctone, que deve ser mais desenvolvido.

Na China, onde, desde o fim da década de 1990, os investidores institucionais ganham em importância, as formas de conhecimento coletivo que estão predominantemente em ação (15 dentre os 21 entrevistados) articulam uma mentalidade conservadora de manipular as regras do sistema em nome de uma racionalidade de longo prazo na administração dos negócios. Apesar das diferenças culturais, é quase o mesmo padrão de pensamento de gestão que nós encontramos nas companhias alemãs. Embora muitas das grandes empresas chinesas tenham se valido das oportunidades que os mercados financeiros ofereceram, elas expressaram que têm tentado proteger, com muito afinco, suas companhias contra a visão curto-prazista de uma economia orientada para o mercado financeiro. As afirmações seguintes são típicas dessa mentalidade: “A longo prazo, nós não aceitaremos nenhum investidor institucional. Eles priorizam seus interesses, não os nossos (CEO chinês na ativa, China, 2013, traduzido do chinês pelos autores). No geral, os resultados da pesquisa indicam que as mentalidades coletivas da maioria dos executivos do Leste Asiático não são neoliberais (ver Tabela 9). Elas são definidas por outros esquemas culturais, oriundos dos sistemas empresariais dentro do quais eles foram socializados.

Tabela 10. A mentalidade de mercado financeiro dos executivos nos países selecionados.

\begin{tabular}{|c|c|c|}
\hline $\begin{array}{l}\text { Mentalidades } \\
\text { coletivas }\end{array}$ & Outros esquemas culturais & Mentalidade de mercado financeiro \\
\hline Alemanha & $\begin{array}{l}\text { Mentalidade defensiva que } \\
\text { manipula as regras do sistema }\end{array}$ & $\begin{array}{l}\text { Mentalidade agressiva do mercado } \\
\text { financeiro }\end{array}$ \\
\hline Coreia & $\begin{array}{l}\text { Mentalidade do modelo sul-coreano } \\
\text { de negócios }\end{array}$ & Contra o mercado financeiro \\
\hline Japão & $\begin{array}{l}\text { Mentalidade do capitalismo dos } \\
\text { bens comuns }\end{array}$ & Contra o mercado financeiro \\
\hline China & $\begin{array}{l}\text { Mentalidade conservadora que } \\
\text { manipula as regras do sistema }\end{array}$ & $\begin{array}{l}\text { Contra o curto-prazismo dos } \\
\text { mercados financeiros }\end{array}$ \\
\hline
\end{tabular}

No que diz respeito ao uso de conceitos de gestão, os grandes conglomerados sul-coreanos se tornaram bastante modernos. Muitos conceitos do momento foram introduzidos, especialmente depois da crise financeira asiática. Todavia, as mentalidades coletivas dos executivos na ativa permanecem muito ligadas a algumas ideias básicas de estilo de liderança que não se remetem aos conceitos 
ocidentais de liderança baseada em resultados, diferentemente de muitos dos executivos alemães. A forma de conhecimento dominante no que concerne à liderança é, ainda, a mentalidade de gestão de redes de reciprocidade. "Liderança" era traduzida, para 19 dentre 24 CEOs sul-coreanos, como a responsabilidade do supervisor de cuidar pessoalmente do bem-estar do empregado. Esse é o caso, inclusive, para a faixa etária dos executivos mais novos, isto é, nascidos entre 1955 e 1964, e está frequentemente relacionada a um ideal de que "somos todos uma família". A tomada de decisão rápida e, se necessário, um sistema de cima para baixo, era natural para esses executivos. Somente 5 executivos sul-coreanos defenderam com afinco a delegação e a participação dos empregados. Os executivos sul-coreanos, assim como os CEOs estrangeiros alocados na Coreia do Sul trabalhando para uma companhia multinacional, estão bem conscientes de que a cultura sul-coreana é uma cultura forte, que permeia todos os conceitos de gestão que são implementados pela firma. Muito frequentemente, as mentalidades coletivas em ação reduzem esses conceitos a formas artificiais que são bastante elegantes e profissionais, mas que, de fato, funcionam como um repaginamento para a companhia. "Eu eliminei todos os níveis baseados na antiguidade, quer dizer, todo o sistema de hierarquias. [...] Ficaram apenas os gestores de equipe e, além deles, os outros, simples gestores. [...] Tudo ficou basicamente horizontalizado. Mas, sabe, embora eu tenha erradicado todos aqueles sistemas hierárquicos, eles sabem quem é o chefe e quem não é. Aquilo ao menos ajudou em uma comunicação mais livre" (CEO sul-coreano na ativa, Coreia do Sul, 2013).

Tabela 11. 0 pensamento de gestão neoliberal dos executivos nos países selecionados.

\begin{tabular}{l|l|l}
$\begin{array}{c}\text { Mentalidades } \\
\text { coletivas }\end{array}$ & \multicolumn{1}{|c|}{ Outros esquemas culturais } & \multicolumn{1}{c}{ Pensamento de gestão neoliberal } \\
\hline Alemanha & $\begin{array}{l}\text { Mentalidade de "conversar } \\
\text { e ouvir as pessoas" }\end{array}$ & $\begin{array}{l}\text { Mentalidade de "liderança movida pelo } \\
\text { rendimento", Mentalidade de "técnico do } \\
\text { time" }\end{array}$ \\
\hline Coreia & $\begin{array}{l}\text { Mentalidade de redes "é } \\
\text { dando que se recebe" }\end{array}$ & Não encontrado \\
\hline Japão & $\begin{array}{l}\text { Mentalidade de } \\
\text { "representar o grupo" }\end{array}$ & Não encontrado \\
\hline China & $\begin{array}{l}\text { Mentalidade de "motivação } \\
\text { do empregado" }\end{array}$ & Não encontrado \\
\hline
\end{tabular}

O tópico da "liderança" pareceu pouco familiar a muitos dos executivos japoneses. Foi bastante complicado identificar qualquer padrão de argumentação consistente sobre o assunto. Como alguns destacaram, isso pode ter origem no sistema de educação e na sociedade japonesa, que enfatiza mais fortemente o 
grupo em vez de um pequeno número de líderes "superiores". 18 dentre os 20 CEOs concordaram que a comunicação com os empregados, refletindo as opiniões dos que estão "embaixo", são valiosas. Segundo tal mentalidade coletiva de "representação do grupo", isso pode induzir a criatividade, participação e responsabilidade dos empregados, a modernização e a construção de estratégias. Essa mentalidade pode ser entendida como um exemplo a ser seguido por CEOs, e inclui que todo o poder de decisão é deixado para o grupo de coexecutivos, e a obrigação do CEO é a de representar adequadamente o grupo de pares, colegas e empregados da empresa. É parte do processo de tomada de decisão típico do Japão, que é chamado de Ringiseido, um sistema de rotação para o recrutamento de CEOs, que oferece - de acordo com a antiguidade, o desempenho e o status - as posições mais altas para os executivos três anos antes de sua aposentadoria. Dentro desse sistema, as decisões e deliberações entre os executivos em todos os níveis abaixo dos diretores devem ter primazia. As decisões executivas, portanto, são posteriores.

A introdução de conceitos de gestão nas empresas chinesas, estatais ou privadas, é bastante influenciada pelo Ocidente. É comum que novos conceitos de gestão sejam introduzidos pelo governo e pelas administrações chinesas com o propósito de assumir e aprender com o pensamento de gestão ocidental. Por exemplo, os conceitos de produção enxuta, gestão da qualidade total e gestão enxuta têm sido implementados nas últimas duas décadas. Além disso, nos anos recentes, gestão de risco e de desempenho são novos conceitos implementados por muitas das grandes empresas estatais. Para aproximadamente 17 dentre os 21 CEOs de empresas privadas e estatais, está em funcionamento uma mentalidade do tipo "aprendendo com os melhores, mas ainda ficando para trás". Ela está fortemente ligada às ambições das suas empresas em correr atrás da concorrência. A liderança, nessa medida, é entendida como uma tarefa cuja finalidade é aperfeiçoar a cultura da empresa e aumentar a motivação dos empregados. Em 10 dos 21 casos, essa mentalidade de "motivação do empregado" está fundida com uma nova filosofia de tomada de decisão e participação de baixo para cima dos empregados. "Eu sou o CEO. Mas eu não tenho que pensar sobre os objetivos do desenvolvimento da empresa. Isso é feito por nossos empregados, de baixo para cima. Eu deixo isso para os chefes de departamento; e os chefes de departamento, para os gerentes seniores. Nós recebemos as ideias de baixo para cima e discutimos nas reuniões da comissão de CEOs, o que é factível e bom para o desenvolvimento da empresa (Presidente de companhia chinesa e CEO na ativa, China, 2013, traduzido do chinês pelos autores). Até aqui, contudo, nem os sistemas de indicadores (exceto para o cálculo de desempenho), nem um estilo de liderança movida pelo resultado se revelaram como mentalidades e técnicas de gestão nas entrevistas chinesas. 


\section{CONCLUSÕES}

Os resultados referentes às duas hipóteses da principal corrente da literatura sobre a globalização são bastante claros. Tanto para a economia alemã, quanto para as do Leste Asiático, o pressuposto das elites globais para o setor industrial corporativo tem que ser rejeitada. A competição e a seleção de pessoal altamente qualificado não implicaram um grande número de pessoal recrutado ao redor do globo no nível mais alto de gestão. Na maioria das vezes, esses executivos foram alocados no exterior como parte do desenvolvimento das suas carreiras na empresa sede no país de origem. Alguns viajam constantemente pelo mundo e acumulam milhões de milhas ao redor do globo, mas não são executivos que pulam de empresa em empresa e têm carreiras transnacionais. Portanto, o efeito da globalização pode ser descrito, nos termos das carreiras de gestão, como "globalização leve", que auxilia na "circulação de cérebros", mas não constitui nova classe mundial da elite econômica no setor industrial corporativo. Por que isso? Por um lado, os economistas nos dizem que os retornos sobre investimentos mútuos são maiores para pessoal altamente qualificado, assim como para as companhias, quando ambos se mantêm uns com os outros (Williamson, 1975, p. 75; LindBeck \& SNower, 1988; Bertold \& FEHN, 1995). Por outro lado, os sociólogos sabem que a confiança, a lealdade e uma profunda compreensão das regras tácitas da companhia são as razões pelas quais quadros formados pela companhia com aquela qualificação são os escolhidos (STROH \& Reilly, 1998; Котthoff, 2006; Pohlmann, 2009). Os quadros internos tampouco estão ávidos para vender, dividir ou arrematar partes da companhia como os de fora, algumas vezes, estão (LuCIER et al., 2007). Se nas grandes companhias industriais das principais regiões do mundo se preferem os quadros internos, por que o executivo deveria ir para o exterior por um longo período, correndo o risco de ficar para trás na carreira dentro do seu país e de sua empresa de origem?

No que diz respeito à segunda hipótese, a da difusão e internacionalização do pensamento de gestão neoliberal, os resultados indicam que a afirmação não se sustenta, pelo menos para as economias do Leste Asiático. Claro, nossos resultados estão relacionados às mentalidades coletivas, ao inventário de conhecimento dos executivos, não lidando, assim, com as medidas organizacionais dentro das companhias. No entanto, ainda assim, a ideia de que haveria uma difusão global do pensamento de gestão neoliberal pode ser refutada. Antes de tudo, descobriu-se que, no nível corporativo, a mentalidade do mercado financeiro neoliberal não está se disseminando pelo mundo. Nos países ocidentais, tais como a Alemanha, a mentalidade dominante é a perspectiva defensiva de "manipular as regras do 
sistema. A maioria dos altos executivos são favoráveis a estratégias de longo prazo para proteger os interesses das suas firmas, burlando o sistema do mercado financeiro. Nas companhias do Leste Asiático, a maioria dos executivos critica a economia orientada para o mercado financeiro, preferindo seus próprios modos autóctones de administrar o negócio (como na Coreia do Sul e no Japão), ou uma abordagem de longo prazo (como na China). Nesse sentido, nossos resultados indicam que os sistemas empresariais sul-coreano e japonês ainda são, no nível das mentalidades coletivas dos executivos, diferentes do sistema de governança corporativa americano centrado nos acionistas (ITAMI, 2000; 2002). Para a China, Xinchun Li destacou, no seu estudo sobre 4256 empresários e executivos chineses, que em apenas raros casos há firmas desse país usando o mercado de ações para financiar suas estratégias corporativas, porque o risco de se perder o controle decisório é considerado muito alto (LI, 2011, p. 76-9).

No que tange ao pensamento de gestão neoliberal sobre liderança, os resultados apontam para um padrão quase idêntico. Na Alemanha, o que basicamente se entendia por liderança mudou bastante, e uma abordagem delegatória radical é a mais comum hoje em dia. Isso é confirmado por outros estudos sobre a cultura da liderança na Alemanha (LeIPPRAND et al., 2012; Busch et al., 2013). As novas mentalidades coletivas do pensamento de gestão neoliberal estão, em um número significante de grandes companhias manufatureiras alemãs, conectadas com a reestruturação organizacional das firmas, que se movem em direção ao estabelecimento de centros de lucro, sistemas de indicadores e benchmarking. Novamente, isso não é o caso na maioria dos conglomerados empresariais sul-coreanos e japoneses. Embora essas companhias tenham estabelecido muitas características bastante modernas de organização do trabalho e conceitos de gestão, não há nenhuma indicação de um estilo de liderança movido pelo resultado - um que não esteja apenas relacionado a medidas de desempenho individual, mas também ao sistema de indicadores e benchmarks para unidades de negócio -, representado nas mentalidades coletivas dos executivos. Na China, onde o uso de conceitos de gestão ocidentais é muito comum, as mentalidades coletivas que dizem respeito à liderança são mais comumente dominadas pela ideia de motivação de pessoal e não foram influenciadas pelo pensamento de gestão neoliberal. Isso também foi confirmado pelo estudo de 4225 empresários e executivos, realizado por Shying Xu et al (2012), que mostrou que motivação e delegação são abordagens dominantes no que se refere à liderança pelos executivos nas empresas chinesas (Xu et al., 2012, p. 97-102).

Os resultados indicam que o pensamento de gestão neoliberal, tal qual expressado pelos pensadores de gestão ocidentais, teve algum impacto na mentalidade 
coletiva dos executivos alemães, mas não atingiu o estoque de conhecimento coletivo dos executivos nas economias do Leste Asiático. Todas essas companhias se tornaram bastante modernas, por exemplo, na repaginação das suas organizações de trabalho e no que se refere à adoção de conceitos de gestão. Contudo, seus esquemas de interpretação permanecem radicados nas suas culturas e, geralmente, não fazem uso do pensamento de gestão neoliberal.

Como esses resultados podem ser explicados? Antes de tudo, as mentalidades coletivas, enquanto formas de conhecimento, estão profundamente enraizadas na cultura e, portanto, não mudam com facilidade em um curto período de tempo (HAll \& SoKICE, 2001). Isso precisa ser levado em conta por todas as correntes teóricas mais difundidas sobre a globalização e sobre a transformação do neoliberalismo. De acordo com os resultados, é mais vantajoso aderir a uma abordagem das "variedades do capitalismo", que leve em consideração as regras institucionais tácitas, os esquemas cognitivos e os sistemas de crenças (STREECK \& Yamamura, 2001; Whitley, 1999; 2009). Partindo de uma perspectiva sociológica, as instituições não somente prevalecem por conta das vantagens que as firmas têm no uso das regras e configurações institucionais nacionais (HALl \& Soskice, 2001), mas também porque elas se tornaram habituais por meio de processos de internalização e socialização.

Em segundo lugar, no que se refere à mentalidade do mercado financeiro, não está muito clara a razão pela qual os executivos deveriam ser favoráveis a uma economia orientada para o mercado financeiro. Executivos deveriam ser responsáveis pelo controle e pela avaliação, além de estar no comando estratégico da empresa. No "picadeiro" do mercado financeiro, como os executivos disseram nas entrevistas, isso não seria mais possível. Quando os donos, os acionistas e os diretores não estão mais interessados na sobrevivência e expansão do grupo empresarial, sobram apenas os executivos para proteger a companhia. Assim, o papel profissional deles, como homens e mulheres da organização, que, na sua maioria, ascenderam na carreira em um único grupo empresarial, é, no nível da economia real, mais o de servir como barreira para a disseminação da mentalidade neoliberal dentro da corporação.

Terceiro, vis-à-vis o mercado financeiro, todos os empresários e executivos nos países selecionados vivenciaram sérias crises financeiras, que levaram ao colapso, ao fechamento e à falência de muitos grandes conglomerados empresariais. Como resultado, é possível observar um forte efeito de período, o que leva à articulação de mentalidades coletivas que não são favoráveis aos mercados financeiros. 
Em quarto lugar, no que diz respeito à mentalidade de gestão neoliberal e à adoção de técnicas de gestão neoliberal, a nova teoria institucional está correta em destacar que as organizações, muitas vezes, adotam o que é moderno ou o que é a moda do momento, não o aplicando em um nível que altere substancialmente as operações e os procedimentos da companhia. A repaginação, a burla do sistema e as regras tácitas são todas características muito comumente usadas pela nova teoria institucional (Meyer \& Rowan, 1977; Powell \& DiMaggio, 1991).

O pensamento de gestão neoliberal, claramente, é apenas uma pequena peça da grande engrenagem do neoliberalismo. Este artigo não se deteve no quadro geral do neoliberalismo (Lim \& JANG, 2006), sobre suas estratégias e ideologias na transformação dos Estados. Entretanto, os resultados explicitam que os executivos não são os operadores da mudança - como se pensava que seriam, acelerando a tendência que orienta a economia para o mercado financeiro. Ademais, as mentalidades coletivas nos vários países não estão se fundindo ou convergindo, e deve-se enfatizar que essas mentalidades coletivas não podem simplesmente ser deduzidas a partir da literatura de gestão. Uma profunda investigação empírica é crucial para explorar e demonstrar como as mentalidades coletivas são muito mais resilientes e culturalmente enraizadas do que afirma a principal corrente da literatura sobre a globalização.

\section{REFERÊNCIAS BIBLIOGRÁFICAS}

ALBERT, Michel. Capitalism against Capitalism. London: Whurr Publishers, 1993.

AMABLE, Brun. The Diversity of Modern Capitalism. Oxford: Oxford University Press, 2003. APPADURAI, Arjun. "Globale ethnische Räume. Bemerkungen und Fragen zur Entwicklung einer transnationalen Anthropologie". In: BECK, Ulrich (Org.) Perspektiven der Weltgesellschaft. Frankfurt: Suhrkamp, p. 11-39, 1998.

BECK, Ullrich. Was ist Globalisierung? Irrtümer des Globalismus - Antworten auf Globalisierung. Frankfurt: Suhrkamp, 1997.

BERTOLD, Norbert \& FEHN, Rainer. "Neuere Entwicklungen in der Arbeitsmarkttheorie".

Wirtschaftswissenschaftliches Studium (Economic Sciences Study), 24(3), p. 110-7, 1995. BLOOM, Nikolas; CHRISTOS, Genakos; RAFFAELLA, Sadun; REENEN, John.

"Management Practices across Firms and Countries". Academy of Management Perspectives, 26(1), p. 12-33, 2012.

BOLTANSKI, Luc \& CHIAPELLO, Ève. Le Nouvel esprit du capitalisme. Paris: Gallimard, 1999. . “The New Spirit of Capitalism”. International Journal of Politics, Culture and Society, 18, p. 161-88, 2005. 
BRÖCKLING, Ullrich. "Gendering the Enterprising Self: Subjectification Programs and Gender Differences in Guides to Success". Scandinavian Journal of Social Theory, 6(2), p. 7-25, 2005.

BUSCH, Rainer; MCMAHON, Robert; UNGER, Alexander; MAY, Christian; WANG, Ya-Cheng. "A Comparison of Leadership Styles between Chinese and German Managers of Chinese Companies in Germany". Chinese Management Review, Vol. 16, N. 2, p. 1-17, 2013.

CARROLL, William K. The Making of a Transnational Capitalist Class: Corporate Power in the 21st Century. London: Zed, 2010.

CASTELLS, Manuel. The Rise of the Network Society: The Information Age: Economy, Society, and Culture. Oxford, Malden: Blackwell, 1996.

CHALAMWONG, Yongyuth. "The Migration of Highly Skilled Asian Workers to OECD Member Countries and its Effects on Economic Development in East Asia”. In: FUKASAKU, Kiichiro; KAWAI, Masahiro; PLUMMER, Michael G; DUVAL, Alexandra Trzeciak (Orgs.) Policy Coherence Towards East Asia, Development Challenges für OECD Countries, Development Center Studies. Paris: OECD, p. 487-526, 2005.

CHOI, Jang-Jip. "Political Cleavages in South Korea”. In: KOO, Hagen (Org.) State and Society in Contemporary Korea. Stanford: Stanford University Press, p. 13-50, 1993. CLEGG, Steward R. "Management, Global Models". In: RITZER, George (Org.) The WileyBlackwell Encyclopedia of Globalization. Oxfort: Blackwell Publishing Ltd, 2012. CROUCH, Collin. The Strange Non-death of Neo-liberalism. Polity Press, 2011.

CUTTS, Robert. An Empire of schools: Japan's Universities and Molding of a National Power Elite. Armonk: M.E. Sharpe, 1997.

DIEHL, Claudia \& DIXON, David. "Zieht es die Besten fort? Ausmaß und Formen der Abwanderung deutscher Hochqualifizierter in die USA”. Kölner Zeitschrift für Soziologie und Sozialpsychologie (Cologne Journal of Sociology and Social Psychology), 57, p. 714-34, 2005.

DIMAGGIO, Paul \& POWELL, Walter W. The New Institutionalism in Organizational Analysis. Chicago: University of Chicago Press, 1991.

DONG, Wonmo. "Regional Cleavage in South Korean Politics". Korea Observer 26(2), p. 1-26, 1995.

DREHER, Sabine. "Vom Wohlfahrtsstaat zum Wettbewerbsstaat? Die Bedeutung der Migration für die Globalisierungsdebatte”. In: HUNGER, Uwe \& SANTEL, Bernhard (Orgs.) Migration im Wettbewerbsstaat. Opladen: Leske+Budrich, p. 13-32, 2003.

DU GAY, Paul \& MORGAN, Glenn. New Spirits of Capitalism? Crises, Justifications, and Dynamics. Oxford: Oxford University Press, 2013. 
DURKHEIM, Emile. “Individuelle und kollektive Vorstellungen”. In: Soziologie und Philosophie. Frankfurt: Suhrkamp, p. 45-83, 1967.

HALL, Peter A. \& SOSKICE, David W. Varieties of capitalism: the institutional foundations of comparative advantage. Oxford: Oxford University Press, 2001.

HOUSE, Robert J; HANGES, Paul J; JAVIDAN, Mansour; DORFMAN, Peter W; GUPTA, Vipin (Orgs.) Culture, Leadership, and Organizations: The GLOBE study of 62 societies. Thousand Oaks: Sage, 2004.

IBM. Capitalising On Complexity. Insights from the Global CEO Study. IBM, 2011.

ITAMI, Hiroyuki. Nihonkei Corporate Governance (Japanese Corporate Governance). Nihon Keizai Sinbun, 2000.

. Jinponsyugi Kigyo: kawarukeiei kawaranugenri (Humanitarian Coroporate: changing and unchanging principals). Nihon Keizai Shinbu, 2002.

KIM, Yong-Hak. Social Networks within Korea: With a special reference to Regional Ties. Berkeley: University of Berkeley Press, 2005.

KONG, Je-Wook. "Hankook Jeonjaengkwa Chaebolui Hyeongseong (The Korean War and the Emergence of the Chaebol)". Kyeongjaewa Sahoe (Economy and Society), 46, p. $54-87,2000$.

KOTTHOFF, Hermann. "Überflüssige Loyalität in großbetrieblichen Sozialbeziehungen der Modellwechsel von Anerkennungsmustern”. In: BUDE, Heinz \& WILLISCH, Andreas. Das Problem der Exklusion: Ausgegrenzte, Entbehrliche, Überflüssige. Hamburg: Verlag Hamburger Edition, p. 225-39, 2006.

LANVIN, Bruno \& EVANS, Paul A. L. The Global Talent Competitiveness Index 2013. Singapore: INSEAD, 2013.

LEIPPRAND, Tobias. Jeder für sich und keiner fürs Ganze? Warum wir ein neues Führungsverständnis in Politik, Wirtschaft, Wissenschaft und Gesellschaft brauchen. WZB, SNV: Berlin, 2012.

LI, Xinchun. "The Financial Market and the Development of Chinese Enterprises: State of the Art, Prospects, Challenges, and Solutions - Report on the Development of Chinese Entrepreneurs". Management World, 6, p. 76-90, 2011.

LIM, Hyun-Chin \& JANG, Jin-Ho. "Neo-liberalism in Post-crisis South Korea: Social Conditions and Outcomes”. Journal of Contemporary Asia, 36(2), p. 442-63, 2006.

LIM, Hyun-Chin \& KIM, Kyung-Dong. East Meets West: Civilizational Encounters and the Spirit of Capitalism in East Asia. Leiden: Brill, 2007.

LINDBECK, Assar \& SNOWER, Dennis. The Insider-Outsider Theory of Employment and Unemployment. Massachusetts: MIT Press, 1988.

LUCIER, Chuck; WHEELER, Steven; HABBEL, Rolf. "The Era of the Inclusive Leader". Strategy + Business, 47, 2007. 
MANNARI, HIROSHI. The Japanese Business Leaders. Tokyo: University of Tokyo Press, 1974. MEYER, JOHN W. \& ROWAN, BRIAN. "Institutionalized Organizations: Formal Structure as Myth and Ceremony”. American Journal of Sociology, 83(2), p. 340-63, 1977.

MÜNCH, RICHARD. Globale Eliten, lokale Autoritäten: Bildung und Wissenschaft unter dem Regime von PISA, McKinsey \& Co. Frankfurt: Suhrkamp, 2009.

NOBEL, Carmen. "Measuring the Efficacy of the World's Managers". Working Knowledge. http://hbswk.hbs.edu/item/6918.html. Boston: Harvard Business School, 2012.

OEVERMANN, Ulrich. "Die Struktur sozialer Deutungsmuster - Versuch einer Aktualisierung”. Sozialer Sinn, 2(1), p. 35-81, 2001.

PARETO, Vilfredo. Vilfredo Paretos System der allgemeinen Soziologie. Stuttgart: Ferdinand Enke, 1962.

POHLMANN, Markus. Der Kapitalismus in Ostasien: Südkoreas und Taiwans Wege ins Zentrum der Weltwirtschaft. Münster: Westfälisches Dampfboot, 2002.

.Die neue Kulturtheorie und der Streit um Werte”. Soziologische Revue, 28(1), p. 3-14, 2005 .

"Globale ökonomische Eliten? Eine Globalisierungsthese auf dem Prüfstand der Empirie”. Kölner Zeitschrift für Soziologie und Sozialpsychologie, 61, p. 513-34, 2009. "Der Geist des Kapitalismus und seine Trägerschichten". In: HESSINGER, PHILIPP \& POHLMANN, Markus. Globalisierung als Autokapitalismus? Prüfstandberichte zum Zustand eines Entwicklungsmodells. Wiesbaden: VSA, 2014. ROBINSON, William I. A Theory of Global Capitalism: Production, Class and State in a Transnational World. Baltimore: Johns Hopkins University Press, 2004. . "Global Capitalism Theory and the Emergence of Transnational Elites". Critical Sociology, 38(3), p. 349-63, 2012.

SACHWEH, Patrick. Deutungsmuster sozialer Ungleichheit: Wahrnehmung und Legitimation gesellschaftlicher Privilegierung und Benachteiligung. Frankfurt am Main: Campus, 2010.

SCHLUCHTER, Wolfgang. Unversöhnte Moderne. Frankfurt: Suhrkamp, 1996.

SCHMIDT, Carmen. “Japan's Circle of Power: Legitimacy and Integration of a National Power". ASIEN, 96, p. 46-67, 2005.

SCHMIDT-WELLENBURG, Christian. "The Neo-Liberal Governmentality of the Firm - Management and Management Consulting at the Beginning of the 21st Century". Zeitschrift für Soziologie (Magazine of Sociology), 38(4), p. 320-41, 2009.

SCHÜTZ, Alfred. Das Problem der Relevanz. Frankfurt: Suhrkamp, 1982.

SCHÜTZ, Alfred \& LUCKMANN, Thomas. Strukturen der Lebenswelt. Vol. 1. Frankfurt: Suhrkamp, 1994.

SKLAIR, Leslie. The Transnational Capitalist Class. Oxford: Blackwell, 2001. 
SOMBART, Werner. Der moderne Kapitalismus. Vol. 1. Leipzig: Duncker und Humblot, 1902. STREECK, Wolfgang. Gekaufte Zeit: Die vertagte Krise des demokratischen Kapitalismus. Berlin: Suhrkamp, 2013.

STREECK, Wolfgang \& YAMAMURA, Kozo (Orgs.) The Origins of Nonliberal Capitalism. Germany and Japan in Comparison. Ithaca: Cornell University Press, 2001.

.(Orgs.) The End of Diversity? Prospects for German and Japanese Capitalism. Ithaca: Cornell University Press, 2003.

STROH, Linda K. \& REILLY, Anne H. "Zählt für Manager noch Treue zur Firma? Was ist dran an dem Vorwurf, Manager seien heutzutage selbstsüchtige Opportunisten, denen es nur um das eigene Wohl geht?”. Harvard Business Manager, 20, p. 9-15, 1998.

SULLIVAN, S. E. \& ARTHUR, Michael B. "The evolution of the boundaryless career concept: Examining physical and psychological mobility”. Journal of Vocational Behavior, 69(1), p. 19-29, 2006.

THOMAS, D. C. \& INKEN, K. “Careers across cultures”. In: GUNZ, Hugh \& PEIPERL, Maury. Handbook of Career studies. Los Angeles: SAGE, p. 451-70, 2007.

ULLRICH, Carsten G. "Deutungsmusteranalyse und diskursives Interview”. Zeitschrift für Soziologie (Magazine for Sociology), 28(6), p. 429-47, 1999.

WATANABE, Masao \& SCHMIDT, Carmen. "Die wirtschaftliche Elite Japans: Rekrutierungsmuster und Netzwerkbeziehungen”. JAPAN aktuell, p. 56-66, 2004. WEBER, Max. Gesammelte Aufsätze zur Religionssoziologie I. Tübingen: Mohr, 1989. WHITLEY, Richard. Divergent Capitalisms: The Social Structuring and Change of Business Systems. Oxford: Oxford University Press, 1999.

. Business Systems in East Asia: Firms, Markets and Societies. Los Angeles: SAGE, 2009.

WILLIAMSON, Oliver E. Markets and hierarchies: analysis and antitrust implications, a study in the economics of internal organization. New York: Free Press, 1975.

WILLKE, Gerhard. Neoliberalismus. Frankfurt, New York: Campus, 2003.

WILLMOT, Hugh. "Spirited Away: When Political Economy Becomes Culturalized”. In: DU GAY, Paul \& MORGAN, Glenn (Orgs.) New Spirits of Capitalism? Crises, Justifications, and Dynamics. Oxford: Oxford University Press, p. 98-123, 2013.

WITT, Michael A. \& REDDING, Gordon (Orgs.) The Oxford Handbook of Asian Business Systems. Oxford: Oxford University Press, 2014.

XU, Shuying; LI, Lan; WANG, Hui; PENG, Siqin; HAO, Dahai; HAN, Zhoulan; ZHANG, Hongyu; WANG, Yunfeng. "Entrepreneurial Perspectives on Human Nature, Management and Performance - Report on the Development of Chinese Enterprises". Management World, 6, p. 96-100, 2012. 


\section{APÊNDICE}

Tabela 3-1. Amostragem por cota proporcional.

\begin{tabular}{|c|c|c|c|c|c|c|}
\hline & $\begin{array}{l}\text { Idade } \\
\text { (anos) }\end{array}$ & $\begin{array}{l}\text { Mulheres } \\
\text { CEOs \% }\end{array}$ & $\begin{array}{l}\text { Educação } \\
\text { superior \% }\end{array}$ & $\begin{array}{l}\text { Engenharia/ } \\
\text { Natural \% }\end{array}$ & $\begin{array}{l}\text { Estudo no } \\
\text { exterior } \%\end{array}$ & $\begin{array}{l}\text { Trabalho no } \\
\text { exterior \% }\end{array}$ \\
\hline $\begin{array}{l}\text { Top } 100 \text { da } \\
\text { Alemanha }\end{array}$ & 53 & $0 \%$ & $95 \%$ & $62 \%$ & $42 \%$ & $63 \%$ \\
\hline $\begin{array}{l}\text { Entrevistas na } \\
\text { Alemanha }\end{array}$ & 54,5 & $2,5 \%$ & $97 \%$ & $54 \%$ & $32 \%$ & $51 \%$ \\
\hline $\begin{array}{l}\text { Top } 100 \text { da Coreia } \\
\text { do Sul }\end{array}$ & 60,7 & $0 \%$ & $99 \%$ & $51 \%$ & $25 \%$ & $38 \%$ \\
\hline $\begin{array}{l}\text { Entrevistas na Coreia } \\
\text { do Sul }\end{array}$ & 60,4 & $0 \%$ & $100 \%$ & $38 \%$ & $29 \%$ & $54 \%$ \\
\hline Top 100 do Japão & 64,6 & $0 \%$ & $100 \%$ & $54 \%$ & $12 \%$ & $24 \%$ \\
\hline Entrevistas no Japão & 63,5 & $0 \%$ & $100 \%$ & $50 \%$ & $20 \%$ & $70 \%$ \\
\hline Top 100 da China & 57,4 & $4,8 \%$ & $95 \%$ & $67,9 \%$ & $8,2 \%$ & $12,3 \%$ \\
\hline Entrevistas na China & 57,3 & $5 \%$ & $70 \%$ & $43,4 \%$ & $0 \%$ & $5 \%$ \\
\hline
\end{tabular}

Tabela 3-2. Faixa etária.

\begin{tabular}{|l|c|c|c|c|}
\hline $\begin{array}{c}\text { Número de } \\
\text { entrevistas }\end{array}$ & $\begin{array}{c}\text { Faixa etária } \\
\text { 1930-1944 }\end{array}$ & $\begin{array}{c}\text { Faixa etária } \\
\mathbf{1 9 4 5 - 1 9 5 4}\end{array}$ & $\begin{array}{c}\text { Faixa etária } \\
\mathbf{1 9 5 5 - 1 9 6 4}\end{array}$ & $\begin{array}{c}\text { Faixa etária } \\
\mathbf{1 9 6 5 - 1 9 7 4}\end{array}$ \\
\hline Alemanha & 45 & 12 & 25 & 0 \\
\hline Coreia do Sul & 4 & 17 & 4 & 0 \\
\hline Japão & 11 & 6 & 3 & 0 \\
\hline China & 4 & 10 & 4 & 3 \\
\hline Total & 64 & 45 & 36 & 0 \\
\hline
\end{tabular}

Tabela 3-3. Passos da análise na interpretação das entrevistas.

1. Seleção: as sequências relacionadas a tópicos específicos foram selecionados de acordo com nossos interesses de pesquisa, mas com uma codificação aberta;

2. Reformulação: foram resumidos, através de paráfrases, os argumentos, as explicações, as narrações na sequência;

3. Abstração do sentido: a estrutura lógica e normativa foi abstraída e interpretada nos termos do que foi avaliado como bom ou mau, de modo a que fosse possível rastreá-la tendo em vista as normas subjacentes por trás dos julgamentos;

4. Abstração da ordem: foram abstraídas a ordem lógica e normativa do curso dos argumentos, descrições e narrações;

5. Comparação: as sequências escolhidas em todas as entrevistas foram comparadas de modo a falsear, modificar e estender as mentalidades coletivas descobertas, assim como identificar os padrões normativos dominantes, mais comuns e mais compartilhados;

6. Contextualização: os padrões normativos e cognitivos foram relacionados à realidade social da constelação de atores, culturas, estruturas de oportunidades e limitações institucionais dentro das quais eles apareceram;

7. Identificação das regras: relacionadas a essa realidade social, foram identificadas as regras típicas que produzem interpretações comuns e ações reconhecidas como dominantes;

8. Explicação: relacionadas com as teorias nesse campo de pesquisa, foi explicado porque essas regras foram reproduzidas ou alteradas, e quais foram as consequências sociais dessas regras. 